\title{
Profesiones de "cuello blanco" para las mujeres: apuntes de sus orígenes en Nuevo León
}

\author{
"White collar" professions for women: notes of their origins in Nuevo León
}

\author{
Norma Ramos Escobar
}

\begin{abstract}
RESUMEN
Desde finales del siglo XIX y en las primeras décadas del XX surgieron los empleos de "cuello blanco", trabajos considerados idóneos para que las mujeres de recursos limitados vieran una posibilidad de allegarse medios económicos cuando ni el matrimonio ni la familia, o simplemente la orfandad, no les asegurara un sustento seguro, lo que paralelamente impulsó la formación comercial de las mujeres mexicanas. El objetivo de este trabajo es documentar, a partir de fuentes primarias y secundarias, el desarrollo de la educación comercial para las mujeres en Nuevo León. Se analizarán los discursos que se construyen en torno a la presencia de las mujeres en los espacios públicos, observaremos las tensiones que se tejen entre la preparación doméstica y la comercial, y concluimos que los estudios de telegrafista, secretaria y tenedora de libros les permitió a las mujeres ser sumamente valoradas en trabajos como la docencia, pero fue más complicado su desarrollo en la administración comercial.
\end{abstract}

Palabras clave: educación comercial, educación doméstica, feminización, docencia, género.

\begin{abstract}
"White collar" jobs emerged from the late nineteenth and the first decades of the twentieth century, these jobs were considered suitable for women with limited resources. They saw a possibility of generating income when neither marriage, nor family, or simply orphanhood did not assure them a safe sustenance, which in parallel promoted the commercial formation of Mexican women. The objective of this work is to document, from primary and secondary sources, the development of commercial education for women in Nuevo León. The discourses that are built around the presence of women in public spaces will be analyzed, and we will observe the tensions that are woven between domestic and commercial preparation, thus concluding that the studies of telegraphy, secretary and bookkeeper, allowed them to be highly valued in jobs such as teaching, however, their development in commercial administration was more complicated.
\end{abstract}

Keywords: commercial education, domestic education, feminization, teaching, gender. 


\section{INTRODUCCIÓN}

Si el día de hoy preguntáramos cuáles son las áreas del trabajo remunerado en la que tienen mayor presencia las mujeres mexicanas, muchos no dudaríamos en contestar que la maquila, otros quizá señalarían que el servicio doméstico y algunos destacarían los empleos ligados a la salud (como enfermeras), la educación (como maestras) y los servicios administrativos (como recepcionistas y secretarias), por mencionar algunos. La masificación de las mujeres en las áreas de servicio administrativo, que es el tema que ocupa este artículo, tiene sus antecedentes en siglo XIX, durante el Porfiriato, como lo apunta Bazant, "el surgimiento de empresas comerciales e industriales, la fundación de bancos y en general el fomento de todo tipo de actividades mercantiles, motivó la creación y el desarrollo de varias clases de carreras comerciales" (Bazant, 2006, p. 254).

En este sentido se impulsó la educación comercial para las mujeres desde las Escuelas Normales y en escuelas técnicas y comerciales que ofertaron estudios de telegrafistas, teneduría de libros, cajeras, oficinistas, modistas, entre otros currículos exclusivos para mujeres.

En este artículo se hace un recorrido por las carreras comerciales feminizadas y se observan los discursos que se construyen en torno a la presencia de las mujeres en los espacios públicos, las tensiones que se tejen entre la preparación doméstica y la comercial.

La integración al mercado laboral y específicamente en el ámbito educativo servirá para ver cómo las mujeres ingresaron a cuentagotas a empleos que se consideraron "idóneos" para ellas, bajo una lógica segregacionista de una histórica división sexual del trabajo, que encasilló a las mujeres para ocupar ciertas áreas laborales. Como se documenta, pocas lograron interesarse en los estudios comerciales, las menos colocarse en empleos de oficina y otras más aprovecharon su experiencia en estas áreas y lograron posicionarse mejor en la docencia como maestras.

Se observan los discursos sobre la educación comercial y doméstica como dos áreas educativas que causaron tensiones, pues la primera abría las posibilidades al trabajo público y la otra eternizaba a las mujeres en el espacio doméstico.

La presencia de las mujeres en la educación básica y superior ha sido una línea de estudio muy consistente dentro de la historiografía de la educación mexicana. Se ha estudiado a las mujeres (como maestras y alumnas) en diferentes temporalidades

Norma Ramos Escobar. Universidad Pedagógica Nacional, Unidad 241, San Luis Potosí, México. Es Doctora en Humanidades por la Universidad Autónoma Metropolitana-Iztapalapa. Entre sus líneas de investigación se encuentran: historia de la educación y género siglos XIX y XX, historia de la niñez en la educación pública, cultura escolar y trayectorias docentes. Ha participado en diferentes congresos nacionales e internacionales relacionados con la historia de la educación e investigación educativa. Es miembro del Sistema Nacional de Investigadores, Nivel 1 y perfil ProdeP. Cuenta con más de 25 publicaciones entre libros, capítulos, artículos y reseñas. Correo electrónico: amronramos75@gmail.com. ID: http://orcid.org/0000-0003-2218-3330. 
y temáticas -véanse por ejemplo los trabajos de López (2001, 2008, 2016a, 2016b), Arredondo (2003), Alvarado (2004), Ramos (2007) y Galván y López (2008) y el nutrido número de ponencias de los últimos encuentros internacionales de Historia de la Educación (2006, 2008, 2010, 2012 y 2014)-. El análisis de esta propuesta dialoga con la perspectiva de género en la historia de la educación. El reciente balance historiográfico que detalla López (2016a) permite conocer las aristas del tema en la historiografía mexicana, señalando que:

La mayoría de los aportes presentados en congresos nacionales e internacionales asumen que el concepto de género contribuye a comprender la construcción cultural de lo femenino y lo masculino en las identidades colectivas e individuales con carácter histórico y particular. La subjetividad femenina y masculina es para los historiadores una reconstrucción social con elementos de ese mundo normativo y simbólico. La condición de ser mujer-maestra en una época determina la correlación de redes de poder, de ciertos sistemas de creencias, de tantas otras prácticas del conocimiento y de ideologías de género que constituyen el trabajo de magisterio ejercido por mujeres. El control del tiempo, del cuerpo y del espacio, la actitud de profesores varones y profesoras, la definición de actividades consideradas sólo de mujeres, así como el desigual acceso a la ciencia y el conocimiento, aparecen en el estudio del currículo escolar [López, 2016, pp. 243-244].

Así, esta propuesta se desplaza entre la historia de las mujeres en la educación y en los entornos laborales, ofreciendo algunos apuntes históricos para documentar el caso de las mujeres nuevoleonesas en México.

\section{Mujeres y espacios Laborales}

En México la historia de la segregación femenina en ciertos ámbitos educativos y de trabajo tiene su antecedente más inmediato durante el siglo XIX cuando los intelectuales y pedagogos liberales sostenían la importancia de educar a la mujer pues esta sería en un futuro la educadora de los hombres y mujeres del mañana, se empezó a cuestionar la necesidad de instruirla pero con un currículo escolar en el cual se le preparara para la vida doméstica y familiar, así como conocimientos básicos de escritura y lectura, como apunta Carmen Ramos:

La domesticidad a la que se sujetó a la mujer -principalmente de las clases altas- la encasillaron a la vida privada de las labores femeniles, y al mismo tiempo, la segregaron del mundo laboral remunerado, condiciones que contribuyeron a la construcción del estereotipo de sumisión y dependencia de la mujer decimonónica [Ramos, 1992, p. 160].

No obstante, no todas las mujeres entraron en este esquema de dependencia y esperaron pasivamente en su hogar el sustento económico, antes bien, como lo han señalado Francois Carner (1992) y Mary Nash (1993), las mujeres de clase baja y media siempre habían trabajado, controlaban negocios, comercios, trabajaban en el servicio doméstico, la elaboración de alimentos y de ropa, pero el hecho de que trabajaran en el ámbito público no las eximía de las labores domésticas ni de la asociación a trabajos ligados al servicio. 
Con los albores de la industrialización a finales del siglo XIX, los estereotipos establecidos sobre el trabajo femenino tuvieron que ser matizados. El papel que desempeñarían las mujeres en las labores manuales requeridas para la industria cambiaría las posturas tradicionales sobre el trabajo femenino, hasta ver con buenos ojos la integración de las mujeres al trabajo remunerado. Con los cambios económicos y la incorporación de la mano de obra femenina como costureras, cigarreras, telegrafistas, encuadernadoras, mecanógrafas, taquígrafas y cajistas, las mujeres se colocaron como sujetos de producción económica, como lo señalan Ramos (1992) y Carner (1992).

Particularmente en Nuevo León a finales del siglo XIX germinaba un proceso de industrialización que abrió sus puertas a las mujeres, se establecieron empresas de corte textil como "La Fama", "La Leona” y "El Porvenir", así como algunas empresas tabacaleras que, para 1902, sumaban más de 500 mujeres que recibían entre 20 centavos y un peso el jornal diario, según documenta Jacobo Castillo, quien resume:

Son tres los aspectos más importantes que se tienen como principal característica del trabajo femenino en la industria regiomontana. El primero es la ocupación en oficios no especializados y que excluyen la industria pesada generando una división sexual del trabajo. El segundo es la ocupación de la mujer en el trabajo textil ya sea ropa, mantas, lienzos, entre otros, también está su ocupación en menor medida en fábrica de cigarros, velas y cerillos. El tercero es su salario evidentemente inferior al que reciben los hombres [Castillo, 2014, p. 22].

Los empleos disponibles para las mujeres, para el caso nuevoleonés, iban en consonancia con lo que los liberales del XIX pensaron para las mujeres, empleos acordes a sus "capacidades". Aunque se sabe muy poco sobre las condiciones del trabajo femenino en el estado de Nuevo León, el censo de 1900 reporta los espacios laborales para las mujeres nuevoleonesas quienes se desempeñaron en actividades de servicio como se indica en la tabla 1.

Como puede observarse en la tabla 1, la mayoría de las mujeres se dedicaban a prestar servicios domésticos, estas mujeres eran por lo regular mujeres pobres, con escasa instrucción; ocurría lo mismo con las trabajadoras manufactureras, solo que su situación era más vulnerable por las excesivas jornadas de trabajo, las condiciones insalubres de los talleres y fábricas y los precarios sueldos. ${ }^{1}$

Las mujeres de clases medias que contaron con estudios básicos de educación elemental no recurrieron a los trabajos arriba mencionados, antes bien ocuparon puestos en el área de los servicios, también llamados "empleos de cuello blanco", como el trabajo de oficina, atención en comercios y la docencia, que resultaron opciones laborales más atractivas pues comparados con los trabajos manuales daban mayor prestigio. "Mujeres que tenían cierta preparación académica se emplearon en

1 En la investigación realizada por Verena Radkau señala que las mujeres en la industria textil trabajaban jornadas de 14 a 16 horas con un salario diario de 22 centavos diarios hasta alcanzar un máximo antes de comenzar la Revolución de 59 centavos (Radkau, 1992, pp. 78-83). 
Tabla 1. Los trabajos desempeñados por las mujeres en Nuevo León en 1900.

\begin{tabular}{lc}
\hline \multicolumn{1}{c}{ Actividad } & Total \\
\hline Servicio doméstico (incluyendo lavanderas y planchadoras) & 5,405 \\
\hline Industria manufacturera (textil, tabacalera y diferentes obreras) & 1,663 \\
\hline Profesoras & 306 \\
\hline Dependientas y encargadas de comercios & 236 \\
\hline Empleadas de oficina (públicas y privadas) & 18 \\
\hline Telegrafistas & 9 \\
\hline \multicolumn{1}{c}{ Fuente: Tabla construida con los datos proporcionados en Parcero (1992, pp. 78-83). }
\end{tabular}

oficinas de gobierno y empresas particulares como: secretarias, archiveras, telefonistas, telegrafistas, demostradoras, vendedoras; los hospitales reclutaron enfermeras y los sistemas escolares maestras" (Scott, 1993, p. 107). Como apunta Scott, los economistas, empleadores, médicos y políticos de aquellos años sostenían que estos trabajos eran ideales para las mujeres, pues se consideraban "adecuados a sus capacidades físicas y a sus niveles innatos de productividad” (Scott, 1993, p. 109). Como se observa en la tabla 1 , si sumamos a profesoras, dependientas, empleadas de oficina y telegrafistas, eran 569 mujeres quienes recurrieron a este tipo de empleos a principio del siglo XX.

En la última década del siglo XIX y las primeras del XX vino la entrada masiva de las mujeres al magisterio. En este proceso de feminización empezaron a encargarse de la educación de los niños y niñas, atraídas por las mimas instituciones educativas que reforzaban la idea de que las mujeres eran las "ideales" para encargarse de la docencia, debido a su vinculación con los cuidados y el trabajo doméstico, no obstante, como veremos más adelante, hubo mujeres que contando con estudios comerciales terminaron siendo docentes.

La mujer trabajadora en la docencia se integró en un área laboral en donde encontraría un campo para su desarrollo profesional, pero al mismo tiempo una profesión que nacía desvalorizada, controlada y con evidentes desigualdades de género. Como ya lo ha señalado Rose-Marie Lagrave, "durante el siglo XX se manifestó la entrada masiva de las mujeres en la educación y en el empleo remunerado, pero al mismo tiempo esta integración estuvo marcada por la desigualdad de oportunidades escolares y por la segregación de las mujeres a ciertas actividades” (Lagrave, 1993, pp. 82-83).

Nuevo León no fue la excepción, pues, como he documentado ampliamente (Ramos, 2007), las condiciones laborales y de género de las primeras maestras que ingresaron al magisterio se pueden resumir en: salarios más bajos que sus compañeros varones -mientras ellos ganaban entre 30 y 60 pesos mensuales, los sueldos de las maestras apenas llegaba de 10 a 15 pesos mensuales-, además se encargaban de los grupos de menor edad y grado, concentrándose en labores de bordados, costuras y primeras letras; no recibían el nombre propio de maestras sino de "ayudantes sin 
título"; era sumamente vigilado su vestido, su comportamiento y la forma de relacionarse con los hombres, permaneciendo el ideal de la maestra célibe, solterona o "sacerdotisa de la educación”, como se les llegó a nombrar en el estado.

\section{EDUCACIÓN SUPERIOR PARA LAS MUJERES}

Para ocupar un oficio en el área administrativa, las mujeres tuvieron que ingresar a lo que entonces se llamó "estudios superiores", 2 es decir que la educación primaria o básica fue insuficiente para poder desempeñarse en empleos de cuello blanco. Las mujeres nuevoleonesas tuvieron pocos espacios de profesionalización más allá de la educación primaria, fue hasta 1892 que se estableció en Nuevo León la Academia para Aspirantes al Magisterio, después llamada Normal de Señoritas. Esta academia era la única opción para las mujeres que decidían realizar estudios superiores. Mediante un aviso publicado en el Periódico Oficial del Estado en diciembre de 1891 se informó de la apertura de la escuela y se dieron a conocer los requisitos, horarios y materias que se impartirían. Las aspirantes debían tener 15 años cumplidos, además de presentar un examen de admisión encaminado a comprobar que habían cursado la primaria.

El primer programa de estudios que se implementó en la mencionada academia estaba encaminado a la profesionalización de las maestras mediante la Metodología Teórico-Práctica como una de las materias más importantes. Además se impartían la ya tradicional Lengua nacional, Física y Química, Aritmética, Sistema métrico, Geometría, Geografía, Historia de México, Higiene y Economía doméstica. Es preciso destacar que, aunque la carrera advertía la profesionalización del trabajo docente, para las mujeres también significó ser profesionales en: ventilado de habitaciones, aseo corporal, artículos de despensa y su conservación, régimen alimenticio, la confección de vestidos, atención de quemaduras y otros accidentes, el gobierno de la casa, labores de mano, entre otros saberes que reafirmaban el trabajo doméstico y que, como se ha señalado en otros estudios, la cantidad de horas dedicadas a dichas labores ocuparon las mejores horas del día de las mujeres. ${ }^{3}$

2 Cabe señalar que, como lo ha documentado Alvarado (2004), los estudios "superiores" eran estudios considerados post-elementales. Las mujeres del siglo XIX solo podían ingresar a la primaria elemental ( $4^{\circ}$ año) y primaria superior ( $6^{\circ}$ año), y aunque desde el gobierno de Juárez se impulsó a los estudios secundarios o superiores para las mujeres a nivel nacional, este proyecto se prolongó hasta 1869 con la formalización de la primera escuela secundaria que terminó convirtiéndose en Escuela Normal de Profesoras en 1890. En algunos estados de la República existieron escuelas de Artes y Oficios o Academias para Señoritas como estudios superiores, pero la gran mayoría de estos eran de corte de educación doméstica y artística.

3 Me refiero al trabajo de Oresta López, quien documenta las horas que las mujeres pasaban bordando en las Academias para Niñas, privilegiando estos saberes sobre materias más científicas, de las últimas solo les daban "barnices” de ciencia (López, 2016b, p. 125). 
Si bien la posibilidad de seguir estudiando una carrera profesional fue un gran logro para las mujeres nuevoleonesas, esto no significó romper con los modelos impuestos de lo que debían ser y hacer. En 1898 así lo expresaba el director de la Normal para Señoritas al terminar el año escolar:

[...] Podrá juzgarse, cómo llena actualmente este plantel la delicada y difícil misión que el Gobierno le ha confiado: misión progresista y redentora, que consiste en dar a la mujer nuevoleonesa una instrucción general, sólida y variada, que la ponga en condiciones de desempeñar dignamente sus importantes deberes, así en la familia como en la sociedad; preparándola a la vez para el ejercicio de diversas profesiones, compatibles con la de su sexo, con las que en caso necesario se baste a sí misma en la satisfacción de las necesidades materiales de la vida: y para que pueda también, llegar a ser valioso contingente de sus aptitudes, a diversas superiores esferas de la actividad social; Especialmente, si abraza la carrera del Magisterio, para la cual tiene extraordinarias dotes, y en la cual puede ser un verdadero elemento de progreso, una vez que con ella modela, en las futuras esposas y madres, las legítimas dispensadoras de la paz y la dicha en el hogar, y las guías expertas y solícitas que han de conducir a las nacientes generaciones por la senda bendita de la virtud y la verdad [AGENL, 1849].

A principio del siglo XX se feminizó el sistema de educación pública en Nuevo León, quedando reflejado a principios de 1920 cuando las escuelas urbanas y rurales estuvieron atendidas por 732 maestras y 139 maestros. En la Normal de Señoritas sorprendía que la inscripción hubiera alcanzado 283 alumnas, mientras que la Normal para Profesores contaba con una matrícula de 52 hombres, situación que el gobernador Ramiro Tamez señaló:

Salta a la vista el aumento que registra este plantel [Escuela Normal para Señoritas] en el número de educandas, que en el de profesores [...] debiéndose esto a la inclinación de la mujer nuevoleonesa hacia las tareas docentes, de las que ha ido eliminado a los seres del sexo masculino, cuyas actividades físicas y mentales los capacitan para labores de otra índole [AGENL, 1918].

Hubo intentos de atraer a las señoritas a otras profesiones dentro la rama de la administración, por ejemplo, la Academia para Aspirantes al Magisterio cambió su denominación por Academia Profesional para Señoritas en 1894, se reformó y se introdujo en sus estudios las carreras de Telegrafía Eléctrica y Contabilidad Mercantil y Fiscal, profesiones que preparaban para trabajar en las estaciones del ferrocarril, en las oficinas y comercios, respectivamente. En el currículo para las telegrafistas se les preparaba en el conocimiento de los aparatos telegráficos y principios científicos en que estos se fundaban; alfabeto nacional y americano; trasmisión y recepción y documentos de las líneas federales de ferrocarriles y particulares. Por su parte, el currículo de las futuras contadoras contenía contabilidad por partida doble, aritmética aplicada a la contabilidad, ejercicios caligráficos, nociones generales de derecho mercantil, escritura en máquina. En ambas carreras se incluía un año de curso preparatorio, con materias como Ejercicios de estilo y gramática española, Aritmética superior, Nociones de física y química, Higiene doméstica. En el segundo curso se incluían una segunda 
parte de Gramática española, Redacción de documentos oficiales, Geografía general, Elementos de historia natural y Economía doméstica (Ordóñez, 1945).

Estas nuevas carreras estuvieron desde su inicio en desventaja con la de Pedagogía (para maestras), pues las prácticas que se incluían como obligatorias para las alumnas de Pedagogía las hacían por las mañanas como ayudantes de escuelas públicas y privadas de Monterrey, y por las noches tomaban los cursos teóricos, mientras que las estudiantes de Telegrafía y Contaduría hacían sus prácticas en las mismas instalaciones de la Academia, bajo supervisión de sus maestros, es decir, la práctica era simulada y no en espacios de interacción, es decir, en comercios, estaciones de telégrafos y oficinas.

Tabla 2. Alumnas inscritas en la Academia Profesional para Señoritas 1896-1909.

\begin{tabular}{|c|c|c|c|}
\hline Año & Pedagogía & Telegrafía & Contabilidad \\
\hline 1896 & 78 & 15 & 6 \\
\hline 1897 & 105 & 7 & 7 \\
\hline 1898 & 107 & Suspendida (falta de alumnas) & 3 \\
\hline 1899 & 99 & 7 & 2 \\
\hline 1900 & 100 & 3 & Suspendida (falta de alumnas) \\
\hline 1901 & 110 & Suspendida definitivamente & Suspendida (falta de alumnas) \\
\hline 1902 & 137 & - & 19 \\
\hline 1903 & 121 & - & 20 \\
\hline 1904 & 132 & - & 12 \\
\hline 1905 & 175 & - & 22 \\
\hline 1906 & 158 & - & 38 \\
\hline 1907 & 162 & - & 33 \\
\hline 1908 & 217 & - & 30 \\
\hline 1909 & 202 & - & 27 \\
\hline Total & 1903 & 32 & 219 \\
\hline
\end{tabular}

Como puede observarse en la tabla 2, hubo poca acogida por parte de las alumnas para hacer estudios comerciales, siendo Pedagogía una opción más exitosa. En 1899 se suspendió la clase de Contabilidad, pues sólo asistían dos alumnas y una de ellas tuvo que salir fuera de la ciudad, por lo que el director de la escuela, Miguel F. Martínez, solicitó al gobernador suspender la clase, expresándose así sobre la alumna que quedaba: "Considero además conveniente informar a esa superioridad que la alumna que ha quedado tiene ya dos años en el curso que estudia, y no manifiesta ninguna en éste mejores adelantos que en el anterior" (AGENL, 1849). 
Dos años después, en 1901, se suspendió definitivamente la carrera de Telegrafía. Una de las razones aducidas fue que las egresadas no encontraban trabajo o no se les quería contratar, a pesar de que en los discursos de fundación de la Academia y los que los pedagogos nuevoleoneses señalaron tiempo después cuando hacían un análisis de la educación de la mujer se mencionaban aspectos para justificar este tipo de profesiones, señalando:

Ofreció a la mujer la misma oportunidad de educación y adquisición técnica que se concede al hombre. Como ejemplo nos basta citar las Carreras de Comercio, que preparan en TaquiMecanografía y las de Artes Manuales y Mecánicas, de producción mercantil, que forman obreras expertas y empleados aptos para dirigir y organizar oficinas e industrias diversas, en la que el porcentaje de mujeres, es, si no superior, igual al del hombre [Ordóñez, 1945, p. 492].

Cuando se intentó explicar el poco éxito que tuvieron las carreras de Telegrafía y Comercio (como se observa en la tabla 2), se aducía que dicha "novedad escolar" que pretendía la "emancipación espiritual de la mujer nuevoleonesa" no pudo vencer "la resistencia social", pues las egresadas tuvieron serios obstáculos para colocarse en oficinas y trabajos relativos a sus estudios. En los años que estuvieron abiertas estas carreras egresaron en total 13 telegrafistas y 162 contadoras desde la apertura de la Academia en 1896 hasta 1927 (cuando desapareció la carrera de comercio), según documentó en su estadística Ordónez (1945, p. 781). Cabría preguntarse: ¿Cómo fue que la Academia tuvo 30 años de vida egresando profesionales de la contabilidad y la telegrafía y no logró consolidarse en esas décadas como una profesión femenina en comparación con el éxito de la carrera de maestra?

Aunque la plana curricular de la carrera de comercio era más extensa históricamente quedó reducida a secretariado, pues se dio más peso a las habilidades de escribir en máquina y llevar correspondencia que a asuntos contables. La misma definición conceptual de "secretaria", como apuntan Hernández y Badía basadas en la definición de la RAE, es la persona "a cuya discreción se confía un secreto, es la encargada de escribir la correspondencia, la encomendada de custodiar los documentos de una oficina, asamblea o corporación” (Hernández y Badía, 2016, p. 125). Como documentan en su escrito, uno de los hitos que fue importante para considerar el secretariado como un empleo femenino fue en 1905 cuando

La marca Remington obsequió un reloj de oro como premio a M. A. Sauders, por ser la primera mujer exploradora de la escritura a máquina. Esta fecha es paradigmática ya que la introducción generalizada de la máquina es paralela a la sustitución paulatina de los varones por personal femenino [Hernández y Badía, 2016, p. 126].

En concordancia con lo anterior, Bazant (2006) señala que en el Porfiriato las clases de taquigrafía y máquina serían más populares sobre todo entre las mujeres.

Para el caso de Nuevo León la incorporación de las mujeres debió ser más tardía, al menos en el espacio práctico, pues si bien profesionalmente se ofrecía como una 
carrera superior para mujeres en la realidad el trabajo era escaso o poco valorado, pues, aunque podrían llevar la contabilidad de un negocio, muy posiblemente quedaron reducidas a dependientas (encargadas) de almacenes y tiendas; como se ve en la tabla 1, en la estadística de 1900, solo 18 mujeres estaban empleadas en oficinas públicas y privadas y solo se registraron nueve telegrafistas.

En síntesis, y como lo apuntaba sucintamente Oresta López, la educación superior para las mujeres en México se movía en "la mediocridad científica" que ponía en primer plano las "habilidades mujeriles", que garantizaba y reforzaba el orden tradicional de género y la función de las mujeres como madres de familia "sin demasiada participación en la vida pública” (López, 2016, p. 21). De ahí quizá que, aunque se le llamara "estudios superiores", lo cierto es que se consideraron más semi-profesiones poco valoradas por los hombres, mal pagadas y de medianas oportunidades, de ahí que empezaran a ser oficios-profesiones que las mujeres fueron ocupando, pero a cuentagotas.

De manera que el estereotipo de la docencia como carrera femenina había tenido su primer triunfo al consolidarse el magisterio como la principal opción de formación y trabajo para las mujeres nuevoleonesas al alcanzar porcentajes mayores, como se ve en las tablas 1 y 2.

\section{UN NUEVO IMPULSO A LA EDUCACIÓN COMERCIAL A PRINCIPIOS DEL SIGLO XX}

Fue con la Revolución Mexicana (en la primera década del siglo XX) que se trastocó el estereotipo de la mujer en general y de la mujer trabajadora en particular debido a que se alteraron costumbres y papeles de las mujeres: se vieron envueltas en los levantamientos revolucionarios y participaron al lado de los ejércitos, suministrando armamento, alimentando a las tropas, como espías e informantes, comandando tropas, como asesoras y redactoras de periódicos disidentes al régimen, entre otras tareas; sus funciones en ese momento más diversificadas las colocaron como miembros activos de una sociedad que pretendía lograr transformaciones en todos los ámbitos (Lau y Ramos, 1993). El modelo de la mujer burguesa dedicada al hogar cada vez más se separaba de la nueva mujer del siglo XX.

La integración de las mujeres en el mercado de trabajo en la educación, en los servicios, como en la industria manufacturera, se vio también reflejada en las organizaciones sindicales en las que participaron para demandar sus derechos -salarios más altos, reducción de jornada, licencia de maternidad y protección de los hijos-. Las luchas femeniles por sus derechos laborales alcanzaron su punto más álgido en las primeras décadas del siglo XX cuando las mujeres - principalmente maestras- ${ }^{4}$

4 Como señala Graciela Hierro, las maestras encabezaron las luchas feministas en México, "las que cambiaron la fisonomía de las mujeres mexicanas de hoy a través de su acción revolucionaria”, 
participaron activamente con los grupos revolucionarios, logrando que en la Constitución de 1917 se concediera la igualdad de la mujer en lo referente a los derechos individuales y laborales, no así en sus derechos políticos, pues el voto femenino sería más tardío.

En este nuevo contexto la mujer trabajadora se colocó en espacios antes vedados para ella.

Los trabajos relacionados con el servicio siguieron siendo receptores de gran cantidad de mujeres que combinaron su tradicional trabajo del hogar con el empleo remunerado, pero esta vez se hizo énfasis en su profesionalización. En Nuevo León se pretendió crear personal calificado para la industria manufacturera, para que las mujeres crearan sus propios negocios o bien se convirtieran en maestras de confección de ropa.

En 1920-1921 se creó la Escuela de Artes y Labores Femeniles "Pablo Livas", como $7^{\circ}$ año escolar para las niñas que concluían estudios de primaria, con el fin de "que las prepararan adecuadamente para desempeñarse mejor, no sólo en el hogar, sino también en la sociedad al bastarse a sí mismas" (Zavala, 2008, p. 127); la carrera se cursaba en un año. La escuela se abrió en abril de 1921 con un total de 230 alumnas, a quienes como principales requisitos de ingreso se les solicitó:

1) Ser mayores de 14 años.

2) Presentar su certificado de $4^{\circ}$ y $6^{\circ}$ año de instrucción primaria.

3) Asistir a clases de gimnasia.

4) Proveerse de libro de texto y demás útiles escolares.

5) Enterarse del Reglamento Interior de la Escuela (Zavala, 2008, p. 129).

Tabla 3. Escuela de Artes y Labores Femeniles "Pablo Livas", 1921.

\begin{tabular}{cc}
\hline Departamento Artes y Labores & Departamento de Comercio \\
\hline Corte y confección & Taquigrafía \\
\hline Economía doméstica & Mecanografía \\
\hline Cocina & \\
\hline Flores & \\
\hline Bordados & \\
\hline Pintura & \\
\hline Repujado \\
\hline Confección de sombreros \\
\hline Conserva de alimentos \\
Calicultura \\
Fuente: Elaboración propia con datos de Zavala, 2008, p. 129.
\end{tabular}

fundaron clubes de mujeres, revistas para mujeres, proclamas políticas, entre otras defendían el divorcio, la educación igualitaria y la participación política (Hierro, 2002, pp. 71-73). 
Las materias que ofrecía el currículo se muestran en la tabla 3, donde se ofertaban dos departamentos, el de Artes y Labores con materias de corte doméstico y el de Comercio con dos asignaturas: taquigrafía y mecanografía.

En 1928 el Departamento de Comercio abrió sus puertas a los hombres que provenían de la Escuela Comercial anexa a la desaparecida Normal para Maestros, lo que amplió el currículo integrando materias de Contabilidad, Aritmética, Gramática, Derecho mercantil, Inglés, Caligrafía, Gimnasia y deportes, Música y Orfeones. Hasta que ingresaron hombres a la Escuela Pablo Livas se profesionalizó la carrera comercial, y no solo eso, se amplió en cantidad de años: mientras la carrera de Artes y Labores femeniles se cursaba en un año, las profesiones de Tenedor de Libros y de Taquígrafo se cursaban en tres y dos años respectivamente, lo que años más tarde definiría su nueva denominación al incorporarse a la Universidad de Nuevo León, en adelante se le conoció como "Escuela Industrial y Preparatoria Técnica Pablo Livas" (Zavala, 2008, p. 132).

No se tiene el dato desagregado de cuántas mujeres optaron por el Departamento de Comercio, lo que sí era evidente es que en las primeras tres décadas del siglo XX la mayoría de las escuelas públicas y privadas de carácter profesional en el área comercial eran en su mayoría para hombres, cítese como ejemplos las escuelas: el Instituto Comercial Neoleonés, las Academias Comerciales Moderna, Morelos, General Zaragoza, Porfirio Díaz y Serafín Peña, y la Escuela del Círculo Mercantil, de larga data en el estado de Nuevo León.

Lo cierto era que se esperaba que la educación que se consideró "profesional" para las mujeres, más allá del sexto año de educación primaria, perseguía la idea de abrir espacios en la esfera pública, como reflexiona Juan Zavala al hacer un recuento de la historia de la educación superior en Nuevo León:

La Escuela de Artes y Labores vino a llenar un hueco en la educación, al brindar a las jóvenes de primaria, una oportunidad para instruirse en las labores y artes que les permitieran, no sólo ser mejores amas de casa, sino también ganarse la vida y ser el sustento de su familia. Pero, además, tal vez de manera insospechada abrió las puertas a un mundo que era casi exclusivo para hombres, en el cual podrían estudiar, trabajar, opinar e inclusive ser independientes. Esto fue fomentado por la naciente muy próspera industrialización de nuestro Estado, que reclamaba personal, tanto masculino como femenino [Zavala, 2008, p. 132].

A la par de las escuelas superiores se fundaron en el estado de Nuevo León academias particulares con carreras técnicas para mujeres para desarrollar oficios como costureras y modistas. Por citar un ejemplo, en la escuela de Corte y Confección Acme - de carácter particular y que se publicitaba con gran éxito en el estado- se enseñaba a coser en máquina. Es interesante mencionar que preparar a las mujeres en estas áreas estuvo muy ligado a considerarlas como sostenes del hogar, al menos así lo señalaba la publicidad de la escuela ACME:

[...] El fin que constantemente me propongo como directora de este Plantel es evitar pérdidas de tiempo y aburrimiento en el aprendizaje quedando formadas perfectas profesoras, en el término de cuatro meses y poniendo como prueba que varias de mis alumnas son el sostén de su familia y 
ostentan orgullosas el Diploma que dignamente recibieron de la Ilustre Inventora Sra. H. A. S. Woolman. El tiempo de 12 años de práctica con el Acme, me hace conocer las grandes ventajas, y eso me anima, a establecer una clase especial de Sastrería para Señores. Doy clases nocturnas para Señoritas también se dan clases de Flores, Bonetería, Bordado y Encaje en máquina. Profa. Srita. Juana Ríos [El Porvenir, 1923, p. 7].

Lo cierto es que ni las academias de comercio ni las técnicas o privadas que ofrecían integrar a las mujeres en espacios de trabajo fuera de lo doméstico lo lograron con éxito. En una nota periodística en 1924, titulada "No habrá puestos públicos ocupados por señoritas" (El Porvenir, 1924a, p. 6), se señala al gobernador del estado de Nuevo León, Porfirio G. González, como responsable del desempleo de treinta taquimecanógrafas que desempeñaban sus labores en las oficinas del gobierno, sin alguna razón aparente; la nota hablaba de despido injustificado. En respuesta a este despido, el mismo periódico reprodujo una nota editorial (sin firma) encabezada "Respuesta al desempleo de las taquimecanógrafas", que entre otras cosas refuerza los imaginarios de la época sobre los deberes de hombres y mujeres con cierto humor y sátira:

Las empleadas [...], ¡serán cesadas todas las empleadas! jno mujeres en ninguna oficina del gobierno! ¿Quare [sic] causa? ¡Chi lo sá! [sic] pero seguramente se han creído que son más eficaces los servicios que los hombres que llevan pantalones que los de los pantalones que debieran llevar hombres. Porque dígase lo que se quiera decir y aléguese lo que se quiera alegar, hay mujeres más hombres que los hombres para desempeñar las tareas que nuestra madre Naturaleza - por un lamentable equívoco- habrá exclusivizado [sic] para el hombre. Por exceso de mujeres (o acaso por falta de hombres que les sirvan de apoyo a mujeres...) éstas fueron obligadas por las necesidades de la vida a confrontarse con la vida y a luchar por la vida y con la vida contra las amarguras de la vida. La verdad que lo han hecho muy bien porque han sabido hacerlo con ventaja. Más cumplidas que los hombres, menos desordenadas que los hombres, mucho más acuciosas que los hombres, más formales que los hombres, mucho más obedientes que los hombres y más inteligentes que los hombres son unas máquinas de hacer trabajo, en tanto que los hombres, los empleados que buscan las moiicies [sic] del gobierno son una máquina que solo sirven para hacer tiempo con la política y para hacer política con el tiempo. Por lo demás, en nuestra época ya no puede alearse ni siquiera que la mujer ha de ser para estarse metida en casa surciendo [sic] los calzones de los hombres, porque habiendo como hay escacés [sic] de hombres ¿a quien [sic] han de surcirle [sic] los calzones? [El Porvenir, 1924b, p. 3].

El texto es interesante porque empieza a cuestionar el hecho de que por "naturaleza" los espacios públicos son exclusivos para los hombres, a la vez que va construyendo un nuevo imaginario en el sentido de señalar que las mujeres son "más cumplidas, formales, menos desordenadas, más obedientes que los hombres", terminando la perorata con la idea de que las mujeres ya no están para quedarse en casa a "zurcir calzones de hombres", sin duda, vemos en este discurso rasgos del protofeminismo nuevoleonés. Lo cierto es que todas (las despedidas) eran mujeres, las cuales fueron mal vistas en los espacios públicos, y que resultaban ser una auténtica competencia para los varones, de ahí descalificarlas por estar en espacios "que no les correspondían". 
Estos devenires por las opciones profesionales para mujeres nos permiten aventurar la hipótesis de que las egresadas de escuelas comerciales y técnicas terminaron por sumarse a la docencia. Como se indica en la figura 1, en un registro de los expedientes de maestras rurales ${ }^{5}$ de la zona sur de Nuevo León, de las 124 documentadas, 61 reportaron tener otras profesiones, algunas de ellas con más de una profesión.

Como puede observarse, 29 profesoras (equivalente al 47\%) habían hecho estudios de corte y confección, y otras 32 profesoras (53\%) reportaron estudios de comercio, teneduría de libros, inglés, taquigrafía y mecanografía, piano y música, y un caso de estudios en caligrafía y ortografía. Cabe destacar que estas señoritas ingresaron al magisterio teniendo estos estudios, lo que para algunos inspectores varones significaba que eran "preparadas", ya que tenían estudios profesionales. El inspector Pedro Moreno se expresaba así del trabajo de dos maestras de esta zona: “tienen preparación profesional muy apreciable adquirida en colegio particular. Se distinguen por su entusiasmo y estricto apego al cumplimiento de su deber" (AHSEP/DGEPE, 1932); no obstante, cuando se trataba de "labores femeniles" no fue considerado como un plus sino como algo "propio de su sexo", no importaba que se hubiera aprendido en una institución.

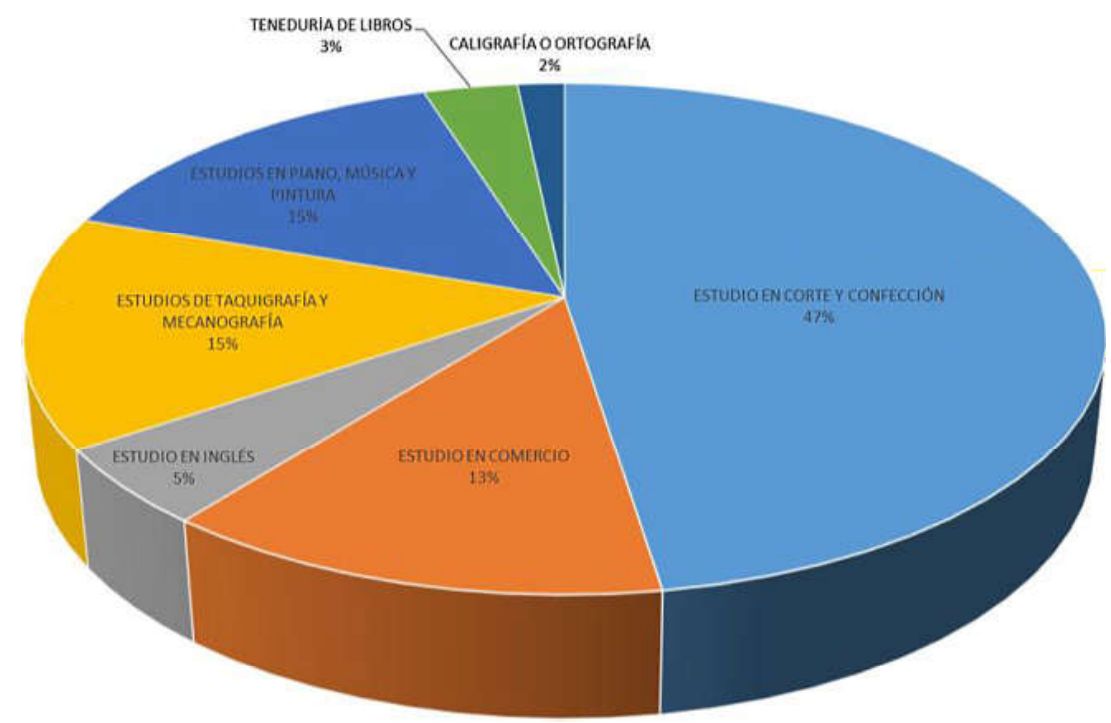

Figura 1. Maestras nuevoleonesas de la zona sur con otros estudios.

De 124 maestras, 61 maestras (el 49\%) reportaron otros estudios.

Fuente: Elaboración propia con datos obtenidos de (AHSEP, s/f).

5 Realicé una investigación sobre las mujeres en los espacios labores y sus trayectorias docentes, señalé que en la zona sur de Nuevo León (la zona escolar más feminizada) trabajaron aproximadamente 300 mujeres en los años que van de 1920 a 1940, sólo pude documentar a 207 de ellas con nombre, apellido y expediente (Ramos, 2007). En este artículo sólo consideré 124 casos que eran los que tenían información sobre otras profesiones y actividades más allá de la docencia. 
Lo cierto es que había maestras que reportaron más de una actividad y hasta seis de las actividades que hacían en la escuela más allá del trabajo docente. De manera que las mujeres con estudios diversos terminaron por enseñar actividades domésticas por sobre las comerciales o administrativas, en un mundo que eternizaba a las actividades domésticas por sobre las técnicas o comerciales para las mujeres. No obstante, creemos que las mujeres con carreras comerciales y técnicas pudieron combinar su experiencia profesional con la docente, muchas de ellas escribían a máquina y sabían llevar "las cuentas", lo que aprovecharon para bien de sus escuelas, entre sus expedientes se ven cartas impecables escritas a máquina con discursos y exigencias claras de profesionistas preparadas.

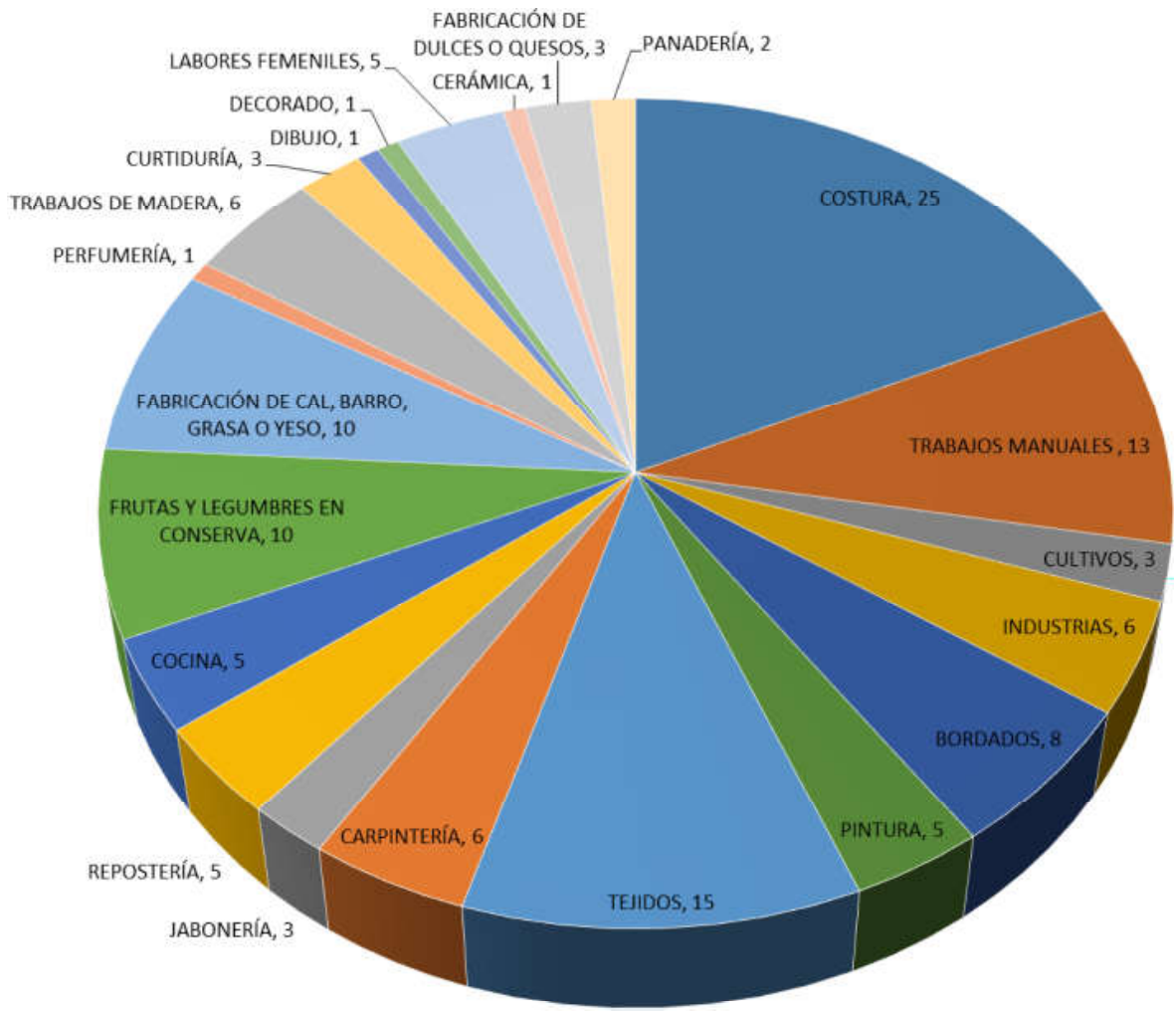

Figura 2. Actividades realizadas por las maestras rurales más allá del trabajo docente.

Total 124 docentes, de las cuales reportaron realizar entre una y seis actividades en la escuela más allá de las tareas docentes.

Fuente: Elaboración propia con datos obtenidos de (AHSEP, s/f).

\section{Para concluir}

La educación comercial para las mujeres nuevoleonesas fue poco exitosa en sus inicios, fue una carrera tardía y poco valorada como actividad para mujeres ya que abría las puertas al espacio público y a las actividades de oficinas, comercios y empresas en donde predominaba la presencia de varones. Se invirtieron pocos recursos 
e infraestructura para que dichas escuelas tuvieran éxito como profesión femenina, antes bien se reforzó como una profesión masculina cuando a principios del siglo XX proliferaron las escuelas comerciales para varones, y este auge tiene que ver con el crecimiento de la ciudad como un polo industrial que atraía en la administración a los varones y, como vimos, las pocas mujeres que lograron trabajar como oficinistas (al menos en el sector público del gobierno) fueron despedidas, sería hasta muy entrado el siglo XX que las mujeres tuvieron una presencia más visible y sólida en los empleos de oficina como secretarias y recepcionistas.

Por otro lado la docencia se había erigido como una profesión ideal para las mujeres, además contaba con un fuerte currículum doméstico, recibió mayor atención, pues toda mujer que estudiara para docente, telegrafista, taquígrafa, tenedora de libros, entre otras, tenía que pasar por un tronco común que la preparaba en economía doméstica y demás habilidades de mujeres, pues en cierto sentido, en caso de no dedicarse a la docencia o a una carrera comercial, las estudiantes egresaban con una fuerte dosis de experiencia doméstica que les sería útil para su vida familiar.

Las mujeres nuevoleonesas que se profesionalizaron a finales del siglo XIX y principios del XX tuvieron que seguir, en grandes porcentajes, los destinos que se diseñaron para ellas: ser maestras.

Para terminar, considero que este recorrido nos invita a pensar en el largo camino que las mujeres han tenido que pasar para poder acceder a una educación superior sin cargas estereotipadas de género; a más de 100 años de que las primeras mujeres accedieron a la educación superior aún hay prácticas, discursos y currículums que violentan el desarrollo pleno y la libre elección de las mujeres en distintas profesiones.

\section{REFERENCIAS}

AGENL [Archivo General del Estado de Nuevo León] (1849). Escuela Profesional para Señoritas [Sección: Educación, Año: 1849-1901, Caja: 1]. Nuevo León, México: Archivo General del Estado.

AGENL [Archivo General del Estado de Nuevo León] (1918). Informe de Gobernador Ramiro Tamez, (1922-1923) [Sección: Memorias de Gobierno, Año: 1918-1929, Caja: 11]. Nuevo León, México: Archivo General del Estado.

AHSEP [Archivo Histórico de la Secretaría de Educación Pública] (s/f). [Sección: Departamento de Escuelas Rurales, Serie: expediente personal (maestras): Sección: Misiones Culturales, Serie: Institutos Sociales]. Ciudad de México, México: Archivo Histórico de la Secretaría de Educación Pública.
AHSEP/DGEPE [Archivo Histórico de la Secretaría de Educación Pública] (1932). [Caja 62, Exp. 13]. Ciudad de México, México: Archivo Histórico de la Secretaría de Educación Pública.

Alvarado, L. (2004). La educación "superior" femenina en el México del siglo XIX. Demanda socialy reto gubernamental. México: CESU-UNAM/Plaza y Valdés.

Arredondo, A. (2003). Obedecer, serviry resistir. La educación de las mujeres en la bistoria de México. México: UPN/ Miguel Ángel Porrúa.

Bazant, M. (2006). Historia de la educación durante el Porifriato. México: El Colegio de México.

Carner, F. (1992). Estereotipos femeninos en el siglo XIX. En C. Ramos (coord.). Presenciay transparencia: la mujer en la historia de México. México: El Colegio de México. 
Castillo, J. (2014). Las mujeres y el trabajo industrial durante el Porfiriato en Nuevo León. En M. Martínez (coord.). Mujeres, trabajo y vida cotidiana en el noreste de México (pp. 9-26). Nuevo León: UANL/Facultad de filosofía y Letras.

El Porvenir (8 nov. 1923).

El Porvenir (3 ene. 1924a).

El Porvenir (4 ene. 1924b).

Galván, L. y López, O. (coords.) (2008). Entre imaginarios y utopias: historias de maestras. México: Publicaciones de la Casa Chata-CIESAS/Colsan.

Hernández, R. y Badía, G. (2016). Elena Cárdenas y su nuevo método de fonografía: un texto para la formación de secretarias en 1908. En L. Galván, L. Martínez y O. López (coords.). Más allá del texto: autores, redes de saber y formación de lectores (pp. 125-142). México: Casa Chata/Colegio de San Luis.

Hierro, G. (2002). De la domesticación a la educación de las Mexicanas. México: Editorial Torres Asociados.

Lagrave, R. (1993). "Una emancipación bajo tutela. Educación y trabajo de las mujeres en el siglo XX”. En G. Duby y M. Perrot (coords.) Historia de las mujeres. El siglo XX. La nueva mujer (pp. 81-117). Madrid: Taurus.

Lau, A. y Ramos, C (1993). Mujeres y Revolución 1900-1917. México: INEHRM/INAH/CONACULTA.

López, O. (2001). Alfabeto y enseñanz̧as domésticas. El arte de ser maestra rural en el Valle del Mezquital. México: CIESAS/CECAH.

López, O. (2008). Porfirianas y revolucionarias: dos estudios de caso de maestras mexicanas. En L. Galván y O. López (coords.). Entre imaginarios y utopias: historias de maestras (pp. 275-306). México: Publicaciones de la Casa Chata-CIESAS/Colsan.
López, O. (2016a). Reflexiones sobre los aportes y retos de la perspectiva de género en la historiografía de la educación en México. En M. Aguirre (coord.). Historia e bistoriografía de la educación en México, 2002-2011, vol. II (pp. 231-248). México: ANUIES/ComIE.

López O. (2016b). Educación, lectura y construcción de género en la Academia de Niñas de Morelia (1886-1915). México: UNAM/PUEG/Colsan.

Nash, M. (1993). Mujeres en España y en Hispanoamérica contemporánea. En G. Duby y M. Perrot (coords.). Historia de las mijeres. El siglo XIX. "Cuerpo, trabajo y modernidad". Madrid: Taurus.

Ordóñez, P. (1945). Historia de la educación pública en el Estado de Nuevo León, "Normal de Profesoras", vol. 2. Monterrey: Gobierno del Estado de Nuevo León.

Parcero, M. (1992). Condiciones de la mujer en México durante el siglo XIX. México: INAH.

Radkau, V. (1984). "La Fama" y la vida. Una fábrica y sus obreras. México: Cuadernos de la Casa Chata/CIESAS.

Ramos, C. (1992). Señoritas porfirianas: mujer e ideología en el México progresista, 1880-1910. En C. Ramos (coord.). Presencia y transparencia: la mujer en la historia de México. México: El Colegio de México.

Ramos, N. (2007). El trabajo y la vida de las maestras nuevoleonesas. Un estudio histórico de finales del siglo XIX y principios del XX. Monterrey: Conarte/Colef/UANL/ Municipio de Monterrey.

Scott, J. (1993). La mujer trabajadora en el siglo XIX. En D. George y M. Perrot (coords.). Historia de las mujeres. El siglo XIX. "Cuerpo, trabajo y modernidad". Madrid: Taurus.

Zavala, J. (2008). Historia de la educación superior en Nuevo León. Monterrey: UANL.

Cómo citar este artículo:

Ramos Escobar, N. (2020). Profesiones de "cuello blanco" para las mujeres: apuntes de sus orígenes en Nuevo León. IE Revista de Investigación Educativa de la REDIECH, 11, e741. doi: https://doi.org/10.33010/ie_rie_rediech.v11i0.741. 